\title{
"HOTEL DES BOOBS" DE DAVID LODGE: PENTECOSTES AO INVERSO
}

Brunilda Tempel Reichmann*

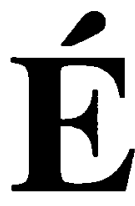

um fato amplamente conhecido que muitos dos escritores de sucesso das últimas décadas na Inglaterra e nos Estados Unidos saíram da Academia, ou seja, são professores universitários e críticos literários além de romancistas. David Lodge é um deles e, assim como Malcolm Bradbury, alcançou fama e sucesso como professor de literatura e crítico literário além de reconhecimento como romancista. Também é notório que a maioria dos romancistas são também contistas. Lodge novamente é um deles. Raros são os escritores que, como Katherine Mansfield, na Inglaterra, e O. Henry, nos Estados Unidos, dedicaram-se apenas ao conto.

Como demonstra sua produção crítica, Lodge acompanhou a evolução da prosa ficional de diversos países neste século e teve contato com a produção experimental "iniciada" por Joyce e Beckett. Ele afirma, no entanto, que sua obra ficcional pertence à tradição realista. ${ }^{1}$ Mas, apesar dessa afirmação, o conto "Hotel des Boobs" demonstra que Lodge foi também influenciado pela ficção francesa (assim como John Fowles e outros) e norte-americana (como

* Universidade Federal do Paraná

I STEVENSON, R. The British Novel Since the Thinties: An Introdiction. London : B. T. Batsford Lid., 1987, p.191. 
Bradbury) da segunda metade do século $\mathrm{XX}$, onde o realismo mescla-se com a "ficcionalidade" na prosa literária. Em "Hotel des Boobs", após criar a ilusão de verossimilhança, ao traduzir ou recriar a realidade como esta se lhe apresenta, Lodge, em determinado momento, abandona a narrativa tradicional e embarca em outra viagem imaginária onde personagem torna-se narrador/autor/personagem; narrativa, texto em composiçāo. ${ }^{2} \mathrm{O}$ início da segunda parte da narrativa é marcado por um estilo diferente do que caracteriza a narrativa tradicional da primeira parte, introduz outros personagens e destrói a ilusão de realidade mantida até então. Em termos estruturais há, portanto, uma clara divisão do conto em duas partes. Não podemos afirmar, no entanto, que elementos da narrativa tradicional não invadem a segunda parte da narrativa ou que na segunda parte da narrativa não haja uma espécie de "confusão proposital " entre elementos da primeira e segunda partes. Essa "confusão" criará um elo entre a figura do personagem da primeira parte e do autor/personagem da segunda, da esposa do personagem da primeira e da esposa do autor/personagem da segunda, sendo que as demais personagens da primeira parte têm, na segunda parte, uma presença marcadamente mais "real" e próxima do autor/personagem e do leitor, ao reagir e falar, do que como personagens da primeira parte, quando são apenas objetos de observação.

\section{Primeira parte do conto}

O início da narrativa, em terceira pessoa, relata a experiência de um casal, Harry e Brenda que, ao contrário dos anos anteriores, quando passavam suas férias na própria Inglaterra, resolvem, agora com os filhos já crescidos e a situação financeira mais estável, passar pela primeira vez as férias na Riviera Francesa. Ao hospedarem-se em um pequeno hotel francês, Harry, de óculos escuros e por trás das páginas de um livro, dedica todo o seu dia a observar minuciosamente os seios desnudos das hóspedes do hotel. Três aspectos característicos da literatura inglesa deste século estão presentes nessa primeira parte do conto: o tratamento realista que o autor dá à sua narrativa, a escolha de um país estrangeiro para o desenrolar da ação e o uso de elementos eróticos. A narrativa realista, como já mencionamos, cria a verossimilhança tão buscada por romancistas através dos tempos e especialmente característica do final do século XIX, na Inglaterra. O uso de outro espaço poético que não o inglês é outra característica de certos escritores ingleses, entre eles E. M. Forster e

2 Outro conto que se tomou bastante popular e que apresenta esse tipo de estrutura é "O Enigma" de John Foules. 
Lawrence Durrell, para dar à narrativa um sabor estrangeiro e exótico e também para contrastar o comportamento dos ingleses ao daqueles de outros países. Para o leitor inglês, apenas essa mudança do espaço já é suficiente para despertar seu interesse e prender sua atenção. Além dessa escolha, existe ainda um forte elemento erótico na primeira parte do conto, que seria um outro recurso usado pelo autor para manter o leitor atento durante o desenrolar da narrativa. Lodge, ao introduzir elementos sensuais e eróticos e mesmo sexuais no conto, estaria dentro de uma outra tradição iniciada por D. H. Lawrence, dentro do romance canônico, nos primórdios do século XX. Lawrence foi o primeiro a abrir as portas para a intimidade dos casais, fechadas pelo puritanismo até a narrativa vitoriana do final do século XIX. Portanto, a narrativa com elementos eróticos passa, desde o início do século XX, a ter um apelo especial também a um público leitor mais sofisticado e a fazer parte do cânone literário, principalmente porque tais elementos são abordados de modo poético ou irônico.

É dentro dessas convençōes literárias que o narrador, anônimo, não participante, da primeira parte do conto relata a experiência de Harry e Brenda na Côte D'Azur. Uma experiência limitada a algumas horas e a um interesse principal: a "fissurassão" de Harry pelos seios desnudos das mulheres inglesas, alemãs, latinas - que tomam sol à margem da piscina do pequeno hotel, já que Brenda acha muito mais confortável permanecer nas imediações da piscina do que sob o tórrido sol e sobre a tórrida areia da praia. Assim descreve o narrador os "objetos" da admiração de Harry:

A Sra Esnobe quase não tinha seios quando estava deitada, apenas leves enchimentos que mais pareciam músculos de meninos, arrematados com engraçados mamilos virados para cima que vibravam como focinhos de dois pequenos roedores quando ela se levantava e se movia. Os seios da alemã eram perfeitos cones, lisos e firmes como se fossem virados sobre um torno mecânico e nunca pareciam mudar de forma não importava a posição que adotava; ao passo que os de Carmen Miranda eram como sacos de cetim marrom cheios de um fluido viscoso que avançava e recuava sobre as costelas em um movimento contínuo quando ela se virava e se contorcia desassossegadamente sobre o colchonetc, aguardando a chamada telefônica do amante ausente. E nessa manhã, havia duas adolescentes na piscina que Harry não tinha visto antes, reclinadas lado a lado, uma com a calcinha de um biquini verde e a outra com uma amarela, admirando os seios recentemente adquiridos, hemis- 
férios lisos e sem defeitos como moldes de geléia, satisfação de donas de casa observando bolos crescer.

Sim, "os meninos de Barnard", colegas de Harry, tinham razão ao dizer que ele era "um fissurado em seios". Brenda, como era de se esperar, está completamente irritada com o comportamento do marido, que chega até a chantageá-la para que ela se comporte como as estrangeiras. O narrador conclui a primeira parte do conto com a seguinte afirmação de Harry: "- Se você tirar a parte de cima do biquini - ele cochichou - eu compro prá você aquele vestido que vimos em St Rafael. Aquele de mil e duzentos francos. ${ }^{4}$

Temos então um espaçamento maior do que no resto do texto e o narrador, ainda anônimo, nos diz: "O autor tinha alcançado este ponto do seu conto, que estava escrevendo..." Essa informação quebra de imediato a ilusão de realidade dentro da qual fôramos lançados pela primeira parte da narrativa e força-nos a encarar "um outro tipo de realidade": aquela em que o suposto real torna-se ficcional, aquela em que o verossimilhante toma-se "diferente", aquela em que a leitura passa a ter o aspecto de um jogo ou de um quebra-cabeças que manterá o leitor atento a cada detalhe da composição da narrativa.

\section{Segunda parte do conto}

O narrador anônimo: a introdução do autor como personagem

A atmosfera que prevalecerá nessa segunda parte do conto não será mais a do erotismo, mas a do receio do autor/personagem de ser descoberto, pelas personagens da primeira parte do conto, como um voyeur. Chegamos então ao "pentecostes ao inverso" onde o vento, talvez uma manifestação do Espírito Santo, sopra violento sobre tudo e sobre todos, não como uma benção, mas como uma punição, e leva pelos ares as folhas do manuscrito do autor.

O autor tinha alcançado este ponto do seu conto, que estava escrevendo sentado numa mesa com guarda-sol no terraço com

3 LODGE, D. "Hotel des Boobs" in: BRADBURY, M. ed. The Penguin Book of Modern British Short Stories. England : Renguin Books,p.326-334. Traduçāo Brunilda Tempel Reichmann. p.2 e 3 . Todas as demais referências a esse texto incluirão o nome do autor, Lodge, e o número da página da tradução.

4 LODGE. p.4. 
vista para a piscina do hotel, usando sua caneta tinteiro e folhas de papel almaço pautadas, como era seu desejo, e tendo acumulado muitas páginas anuladas e reescritas, como era também seu desejo, quando, sem aviso, um poderoso vento soprou. Ele fez com que os pinos nas imediações do hotel tremessem e assobiassem, ergueu pequenas ondas na superfície da piscina, derrubou vários guarda-sóis, e rodopiou as folhas do manuscrito do escritor pelos ares. Algumas delas flutuaram de volta ao terraço ou sobre as margens da piscina, ou mesmo sobre a água da piscina, mas muitas foram funiladas com velocidade estarrecedora pelos ares, sobre as árvores, pelo ar quente do vento. $O$ autor ergueu-se cambaleando e observou embasbacado as folhas de papel almaço erguendo-se mais e mais alto, como pipas que vão se contorcendo contra o sol, brancas contra o céu de anil. Era como a visitação de algum deus ou demônio, um petencoste ao inverso, retirando palavras ao invés de colocá-las. $\mathrm{O}$ autor se sentiu violentado. As mulheres que tomavam banho de sol ao redor da piscina, como se similamnente conscientes, cobriam seus seios nus enquanto se erguiam e observavam as folhas de papel que se retorciam e se perdiam na distância. Faces viravam-se em direção ao autor, sorrisos de simpatia mesclados com Schadenfreude. ${ }^{5}$ Convocados pela voz áspera da mãe, os gêmeos ingleses correram ao redor da borda da piscina juntando folhas soltas para trazê-las com avidez canina de volta ao seu dono. $O$ alemão, que estivera na piscina na hora do vento, veio com duas folhas encharcadas, cobertas com uma caligrafia que chorava, seguras entre dedo e dedão e colocou-as cuidadosamente na mesa do autor para secar. Pierre, - garção, apresentou uma outra folha na sua bandeja. "Cést le petit mistral,"6 ele disse com um moue de comiseração. "Quel domage!" 8 autor agradeceu-lhes mecanicamente, seus olhos ainda voltados em direção às folhas levadas pelo vento, agora meros pontos na distância, a fundando lentamente no bosque de pinos. Ao redor do hotel o ar estava parado novamente. Vagarosamente os hóspedes retornavam às suas espreguiçadeiras e colchonetes. As mulheres descobriam seus seios discretamente, renovavam a aplicação de Ambre Solaire e retomavam à perseguição do bronzeado perfeito. ${ }^{9}$

5 Malícia.

6 Mistral: vento violento, frio e seco, que sopra no golfo de Lião e na região sul da França (Michaelis).

7 Beiço espichado.

8 Que pena!

9 LODGE, p.4. 
O narrador, como podemos notar na passagem acima, continua sua narrativa em terceira pessoa e não adentra o espaço da obra literária como outros narradores que se tornam participantes na diegese do romance ou do conto. No entanto, ele cria um outro personagem, ou seja, cria um conto dentro do conto onde o personagem principal assume o papel de autor/personagem, como demonstra o diagrama abaixo:

\begin{tabular}{|l|l|l|}
\hline & \multicolumn{1}{|c|}{$\begin{array}{l}\text { conto dentro do conto } \\
\text { personagens: } \\
\text { autor e esposa }\end{array}$} \\
autor & $\begin{array}{l}\text { lonto } \\
\text { personagens: Harry and Brenda }\end{array}$ \\
\hline
\end{tabular}

Após o pavor que lhe causa a preocupação das mulheres e dos demais presentes com o acontecido, a perda de seu manuscrito, o autor/personagem encontra-se finalmente só em seu quarto. Após algum tempo o narrador anônimo relata que a esposa do autor/personagem entra no quarto e anuncia que trouxera o vestido mais lindo de St Rafael, fazendo assim a primeira conexão entre sua presença como esposa do autor/personagem no conto dentro do conto e Brenda, esposa de Harry, da primeira parte do conto, e abrindo espaço para que o autor/personagem se transforme em narrador/autor/personagem.

\section{A transformação do personagem "autor" em narrador}

No início da segunda parte o narrador anônimo relata o infortúnio do "autor". Agora o "autor" encarrega-se de relatar seu próprio infortúnio. Sua esposa não pode conter o riso quando escuta o que acontecera e quando sente a preocupação do marido com a folhas do manuscrito levadas pelo vento.

A mulher do autor explodiu em riso. - Você é um tolo - ela disse. - Não foi minha culpa - ele protestou. - O vento surgiu do nada. - Um ato de Deus?

10 O narrador/autor/personagem será referido de ora em diante como "autor", designação que the é dada pelo narrador anônimo. Para que nāo haja confusão entre a figura do autor (David Lodge) e o autor como personagem da segunda parte do conto, usaremos a palavra autor entre aspas. 
- Precisamente.

- Bem, não creio que Ele aprovaria aquele conto. Não posso dizer que eu mesma tenha me interessado muito por ele. Como iria terminar?

A mulher do autor conhecia a história muito bem até o ponto em que ele chegara, porque ele lera o conto para ela na noite anterior. 11

A partir desse momento, a esposa do "autor" passa a ser a ouvinte do suposto final do conto onde Harry e Brenda são os personagens principais. $O$ "autor" relata que Brenda aceitara a chantagem de Harry e saira sem a parte de cima do biquini e, ao permanecer assim na borda da piscina, exacerba o desejo do marido a tal ponto que ele fica com sinais aparentes de excitação sexual durante todo o dia e mal pode esperar para ir para a cama naquela noite. Como o final do conto de Harry e Brenda está ainda sendo elaborado mentalmente pelo "autor", existem alguns detalhes, tal como a separação de Harry e Brenda ao deixarem a piscina, que ainda não foram trabalhados, como ele próprio afirma. Mas, mesmo sem poder esclarecer alguns detalhes, o "autor" continua dizendo que Harry vai só ao quarto e, como Brenda não aparece em seguida, dorme por mais de duas horas. Ao regressar, Brenda torna-se a narradora dentro da narrativa do "autor" ao contar a Harry sobre o buquê que ganhara ao ser eleita a mulher com os seios mais bem formados da semana e de sua transa com Antoine, o garção que lhe entregara o buquê.

A narrativa do "autor" é intercalada por reações e interpelações da esposa que não aprecia muito a história, assim como Brenda não apreciara o comportamento de Harry. O "autor" continua: Harry ao ouvir seu "equipamento genital" ser comparado desfavoravelmente ao do francês, esbofeteia Brenda que então vai para a cama. Ao acordar, duas horas mais tarde, ela vê Harry parado perto da janela "olhando fixamente para a piscina vazia, um azul fantasmagórico sob a luz da lua." 12 Ao insistir para que Harry vá se deitar, Brenda confessa que inventara toda aquela história para ensinar-lhe uma lição. Harry, no entanto, ouve mas não parece escutar o que Brenda lhe diz. Ele está completamente preocupado com o seu próprio corpo: "Nunca pensei, disse Harry, com uma voz sumida, que você se importava com o tamanho do meu pau. "13 Em vão Brenda tenta convencê-lo do contrário. O "autor" então conclui: "Harry sacode a cabeça como quem não acredita, fixando seu olhar nas margens azuis e despeitadas da piscina. Era assim que o conto iria terminar

11 LODGE, p.5.

12 Ibid

13 Ibid 
- as margens azuis e despeitadas da piscina. ${ }^{14}$ Essa é a suposta conclusão do conto que nesse momento está sendo elaborado mentalmente e narrado oralmente pelo "autor" para sua esposa e do conto que estava sendo escrito pelo narrador anônimo. Resta sabermos o que acontece no conto dentro do conto. Percebemos, no entanto, que o diagrama que apresentamos anteriormente deve ser alterado, pois o que era o conto narrado por um narrador anônimo passa a ser um "conto dentro do conto dentro do conto" agora tendo não mais um narrador anônimo a contar a história, mas um narrador anônimo que escreve a história que o "autor" anônimo conta, como demonstra o diagrama abaixo:

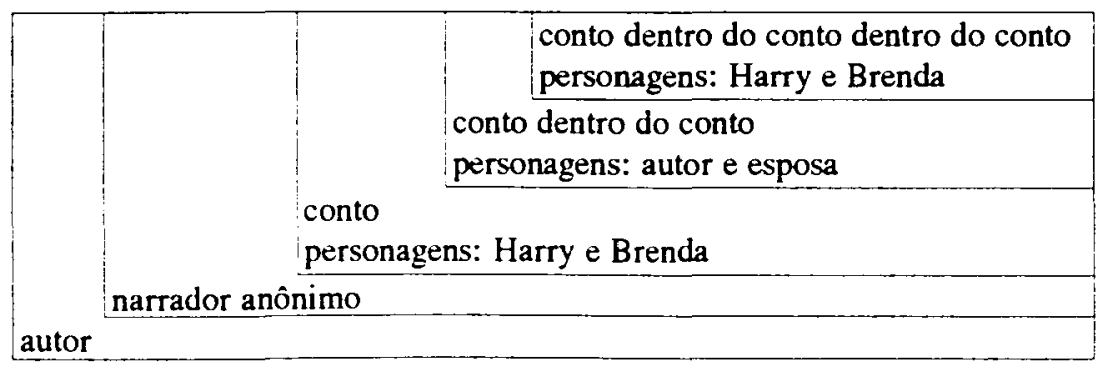

Ao concluir "o conto dentro do conto dentro do conto", encontramos o "autor" no mesmo local e com a mesma postura de Harry. Ele observa "as margens azuis e despeitadas da piscina" e explica: "A fixação de Harry pelos seios das mulheres, você vê - disse o autor, - foi deslocada pela ansiedade sobre seu próprio corpo da qual ele nunca se livrará". ${ }^{15}$ o "autor" e a esposa observam então Pierre, outro garção, a mover-se entre os guarda-sóis e as mesas ao redor da piscina, e comentam que ele é provavelmente homossexual. O "autor" expressa seu alívio por não ter chegado até essa parte do conto escrito, estabelecendo assim um dos vários vínculos entre si e a figura do narrador anônimo da primeira parte do conto. A ansiedade do "autor" continua grande e ele expressa novamente a necessidade de mudarem de hotel. No parecer de sua esposa, o conto, como ele se apresenta agora, parece-lhe muito melhor. Isto é, ela está incluindo a figura de seu marido/autor e o acidente da perda do manuscrito dentro da diegese que inclui Harry e Brenda. A discussão volta-se então para o título que o conto deveria ter. Para o "autor" ele deveria intitular-se "Olho por olho". Brenda, no entanto não concorda. Ela diz: "- Não, chame de 'Hotel dos Peitos'... Delas e seus". ${ }^{16}$ Alcançamos então a conclusão: "Mais

14 LODGE, p.6.
15 Ibid.
16 Ibid. 
tarde naquela noite, quando estavam na cama e quase tinham pegado no sono, a mulher do autor disse: -Você não quer que eu saia sem a parte de cima do biquini, não é?" ${ }^{17}$, respondendo assim à proposta que Harry fizera a Brenda no conto escrito pelo narrador anônimo. O "autor" diz que não, "mas ele não soara inteiramente convencido ou convincente ${ }^{n} .{ }^{18}$ Vemos portanto que a figura da esposa confunde-se novamente com Brenda e que a figura do "autor", além de se confundir com o narrador anônimo, confunde-se também com Harry e os sentimentos daquele parecem ser os mesmos deste. Nota-se uma certa tristeza e decepção no "autor" ao perceber que não sentirá os olhares ávidos dos outros homens, desejosos de tocar os seios de Brenda, nesse caso sua esposa, e no entanto impossibilitados de fazê-lo. Nem inteiramente convencido, nem convincente, assim termina o conto dentro do conto que une e arremata todas as narrativas que se desenvolveram da primeira, aquela iniciada pelo narrador anônimo.

\section{RESUMO}

Este trabalho apresenta uma análise estrutural do conto "Hotel des Boobs" de David Lodge para demonstrar que o mesmo possui caracteristicas tradicionais e convencionais (primeira parte do conto) e características experimentais (segunda parte do conto). O estudo mostra também a metamorfose que sofre o narrador anônimo e o personagem da primeira parte, amalgamando suas funções e acrescentando mais uma, a de autor, tornando-se assim narrador/autor/personagem na segunda parte.

Palavras-chave: Crítica literária, Literatura inglesa, Conto.

\footnotetext{
ABSTRACT

This paper presents a structural analysis of the short story "Hotel des Boobs" by David Lodge to show that the first half is traditional and conventional while the second half is experimental. Besides that, the work also demonstrates the metamorphosis suffered by the anonymous narrator and the character of first part, amalgamating both functions and including another one, that of the author, becoming thus the narrator/author/character in the second part.

17 LODGE, p.6

18 lbid.
} 


\section{REFERÊNCIAS BIBLIOGRÁFICAS}

LODGE, D. "Hotel des Boobs" in BRADBURY, M. ed. The Penguin Book of Modern British Short Stories. England Penguin Books, p. 326-334. Tradução de Brunilda Tempel Reichmann.

STEVENSON, R. The British Novel Since the Thirties: An Introduction. London : B. T. Batsford Lida., 1987. 